\title{
A Critical Role for the Hippocampus and Perirhinal Cortex in Perceptual Learning of Scenes and Faces: Complementary Findings from Amnesia and fMRI
}

\author{
Matthew E. Mundy, ${ }^{1,2}$ Paul E. Downing, ${ }^{3}$ Dominic M. Dwyer, ${ }^{1}$ Robert C. Honey, ${ }^{1}$ and Kim S. Graham ${ }^{1}$ \\ ${ }^{1}$ Wales Institute of Cognitive Neuroscience, School of Psychology, Cardiff University, Cardiff CF10 3AT, United Kingdom, ${ }^{2}$ School of Psychology and \\ Psychiatry, Clayton Campus, Monash University, Victoria 3800, Australia, and ${ }^{3}$ Wales Institute of Cognitive Neuroscience, School of Psychology, Bangor \\ University, Gwynedd LL57 2AS, United Kingdom
}

It is debated whether subregions within the medial temporal lobe (MTL), in particular the hippocampus (HC) and perirhinal cortex (PrC), play domain-sensitive roles in learning. In the present study, two patients with differing degrees of MTL damage were first exposed to pairs of highly similar scenes, faces, and dot patterns and then asked to make repeated same/different decisions to preexposed and nonexposed (novel) pairs from the three categories (Experiment 1). We measured whether patients would show a benefit of prior exposure (preexposed $>$ nonexposed) and whether repetition of nonexposed (and preexposed) pairs at test would benefit discrimination accuracy. Although selective HC damage impaired learning of scenes, but not faces and dot patterns, broader MTL damage involving the HC and PrC compromised discrimination learning of scenes and faces but left dot pattern learning unaffected. In Experiment 2, a similar task was run in healthy young participants in the MRI scanner. Functional region-of-interest analyses revealed that posterior $\mathrm{HC}$ and posterior parahippocampal gyrus showed greater activity during scene pattern learning, but not face and dot pattern learning, whereas $\mathrm{PrC}$, anterior $\mathrm{HC}$, and posterior fusiform gyrus were recruited during discrimination learning for faces, but not scenes and dot pattern learning. Critically, activity in posterior $\mathrm{HC}$ and PrC, but not the other functional region-of-interest analyses, was modulated by accuracy (correct $>$ incorrect within a preferred category). Therefore, both approaches revealed a key role for the $\mathrm{HC}$ and $\mathrm{PrC}$ in discrimination learning, which is consistent with representational accounts in which subregions in these MTL structures store complex spatial and object representations, respectively.

\section{Introduction}

Although it is undisputed that medial temporal lobe (MTL) structures, including the hippocampus (HC) and perirhinal cortex $(\operatorname{PrC})$, participate in memory, their exact role remains controversial (Burgess et al., 2001; Eichenbaum et al., 2007; Squire et al., 2007; Brown et al., 2010; Graham et al., 2010; Montaldi and Mayes, 2010; Ranganath, 2010). A current debate is whether these regions, or subareas within them, differ in their contribution to learning and memory for distinct categories of visual stimuli (Diana et al., 2008; Aly et al., 2010; Preston et al., 2010; Duarte et al., 2011; Watson et al., 2012).

For example, recent neuropsychological studies have revealed that selective bilateral $\mathrm{HC}$ damage impairs recognition memory

\footnotetext{
Received June 22, 2012; revised March 21, 2013; accepted April 10, 2013

Author contributions: M.E.M., P.E.D., D.M.D., R.C.H., and K.S.G. designed research; M.E.M. performed research; M.E.M., P.E.D., and K.S.G. analyzed data; M.E.M., P.E.D., D.M.D., R.C.H., and K.S.G. wrote the paper.

This work was supported by the Wales Institute of Cognitive Neuroscience and the BBSRC (Grant \#BB/1007091/1). The Wales Institute of Cognitive Neuroscience was set up by a cross-institution grant from the Welsh Government to the Schools of Psychology at Cardiff, Bangor, and Swansea Universities. We thank our colleagues at the Cardiff University Brain Research Imaging Centre, particularly John Evans and Martin Stuart, for help with the scanning protocol and data collection, Andy Lee for providing Figure 1, and Chris Chambers, Andrew Lawrence, and Ed Wilding for comments on the manuscript.

This article is freely available online through the J Neurosci Author Open Choice option.

Correspondence should be addressed to Prof. Kim Graham, School of Psychology, Cardiff University, Tower Building, Cardiff, CF103AT, United Kingdom. E-mail: grahamks@cardiff.ac.uk.

DOI:10.1523/JNEUROSCI.2958-12.2013

Copyright $\odot 2013$ the authors $\quad 0270-6474 / 13 / 3310490-13 \$ 15.00 / 0$
}

(Bird et al., 2007), discrimination learning (Graham et al., 2006), and odd-one-out decisions (Lee et al., 2005a) for scene, but not face, stimuli. In contrast, larger MTL lesions that encompass both the HC and $\mathrm{PrC}$ result in poor long-term memory for scenes and faces (Taylor et al., 2007) and reduced discrimination accuracy for scenes, faces, and objects (Barense et al., 2005, 2007; Lee et al., 2005b). Critically, however, these domain-specific patterns are not present in all patients and there is disagreement over the exact anatomical locus of such deficits (Levy et al., 2005; Shrager et al., 2006; Kim et al., 2011). It has been suggested that concomitant involvement of domainsensitive regions in parahippocampal cortex and/or fusiform gyrus, rather than damage to the $\mathrm{HC}$ and $\mathrm{PrC}$ per se, may underlie such stimuli-dependent functional dissociations (Squire et al., 2006; Suzuki, 2009, 2010 but see Baxter, 2009; Graham et al., 2010; Jeneson and Squire, 2012; Lee et al., 2012; Rudebeck et al., 2013).

We undertook complementary patient and $\mathrm{PMRI}$ experiments to address this issue, investigating whether the $\mathrm{HC}$ and $\mathrm{PrC}$ would play distinct domain-sensitive roles in a novel learning task in which performance on scenes and faces were compared directly alongside an equally difficult visual control (dot patterns). In Experiment 1, two amnesic patients (one with selective $\mathrm{HC}$ damage and another with damage including the $\mathrm{HC}$ and $\mathrm{PrC}$ ) and 12 matched controls were preexposed to pairs of visually similar faces, scenes, and dots. Subsequently, they made repeated same/different judgements to both previously exposed and nonexposed pairs. This paradigm allowed us to determine whether patients could learn to discriminate faces, scenes, 
and/or dots as measured by either an accuracy advantage for preexposed compared with nonexposed pairs (Analysis 1A) and/or by increasingly better discrimination success as same/different discriminations were repeated during the test (Analysis 1B). In Experiment 2, we aimed to elucidate the unique contributions of the $\mathrm{HC}$ and $\mathrm{PrC}$, alongside the parahippocampal and fusiform areas, to perceptual learning. Young healthy participants performed a version of the task used in Experiment 1. A functional region-of-interest (fROI) approach was adopted, complemented by whole-brain analyses, to determine which brain regions showed a difference between preexposed versus nonexposed scene, face, and/or dot pairs (Analysis 2A) and how brain activity was modulated by decision accuracy (correct $>$ incorrect, Analysis 2B).

\section{Materials and Methods \\ Experiment 1: patients \\ Participants}

Two patients with damage to the MTL (initially reported in Lee et al., 2005b, as patients HC3 and MTL3) and 12 healthy participants matched to the patients for age and education were included in Experiment 1. The two patients were selected for the study based on definitive evidence of circumscribed involvement of the MTL, neuropsychological confirmation of selective difficulties with episodic recall, and willingness to take part in our study (Barense et al., 2005; Lee et al., 2005b; Graham et al., 2006; Barense et al., 2007; Lee and Rudebeck, 2010a; Rudebeck et al., 2013). Qualitative and quantitative measures of the patients' brain damage, as well as detailed neuropsychology, have been published previously (Lee et al., 2005b; Lee and Rudebeck, 2010a). Patient HC3, a 50-year-old woman with 10 years of education, has selective bilateral $\mathrm{HC}$ involvement after an episode of carbon-monoxide-induced hypoxia. MTL3, a 64-year-old woman with 10 years of education, has a larger bilateral lesion to the MTL that includes damage to both the $\mathrm{HC}$ and PrC. Use of a standard functional localizer in both patients confirmed activation in parahippocampal place area (PPA), fusiform face area (FFA), and lateral occipital cortex, a profile consistent with the pattern of structural integrity evident from volumetric and connectivity analyses of the patients' structural MRI scans (Lee and Rudebeck, 2010a; Rudebeck et al., 2013; Figure 1).

On neuropsychological testing, the patients showed exceptionally poor episodic recall of both verbal and visual material. For example, both scored 4 of 50 on delayed recall of a prose passage (logical memory) and were similarly poor at reproducing the Rey-Osterrieth Complex Figure after a delay (HC3, 3 of 36; MTL3, 4.5 of 36) despite good initial drawings (HC3, 35 of 36; MTL3, 30.5 of 36). Recognition memory in HC3, as measured using the Warrington Recognition Memory Test, was within the normal range for faces and scenes, but not words, whereas MTL3 showed impairment in all three recognition memory tasks. This pattern is consistent with the patients' performance on other experiments in which we have investigated recognition memory performance across visual categories (Taylor et al., 2007). Other measures of cognition, including visual processing (as measured by the Visual Object and Space Perception Battery, see also copy of the Rey-Osterrieth Figure described earlier) and problem solving were preserved in both the patients (Lee et al., 2005b), although MTL3 showed some difficulties with semantic memory as evidenced by a mild deficit on category comprehension and semantic association tasks (Lee and Rudebeck, 2010a).

Two groups of six neurologically healthy control participants (male and female) age and education matched to the patients were recruited from the Cardiff University School of Psychology Community Panel. The controls for patient HC3 had a mean age of $53.3 \pm 2.9$ years and $9.8 \pm 1.0$ years of education; matched controls for MTL3 were on average $62.3 \pm 4.1$ years of age with $10.0 \pm 0.6$ years of education. Because analyses of the visual discrimination data obtained from these two groups revealed no significant differences in accuracy or reaction time (RT) across any of the three experimental conditions (all $F<1$ ), the two groups were combined into a single group for comparison with the patients (age, $57.8 \pm 5.8$ years; education, $9.9 \pm 8.2$ years). There was no significant difference between the patients and the larger control group

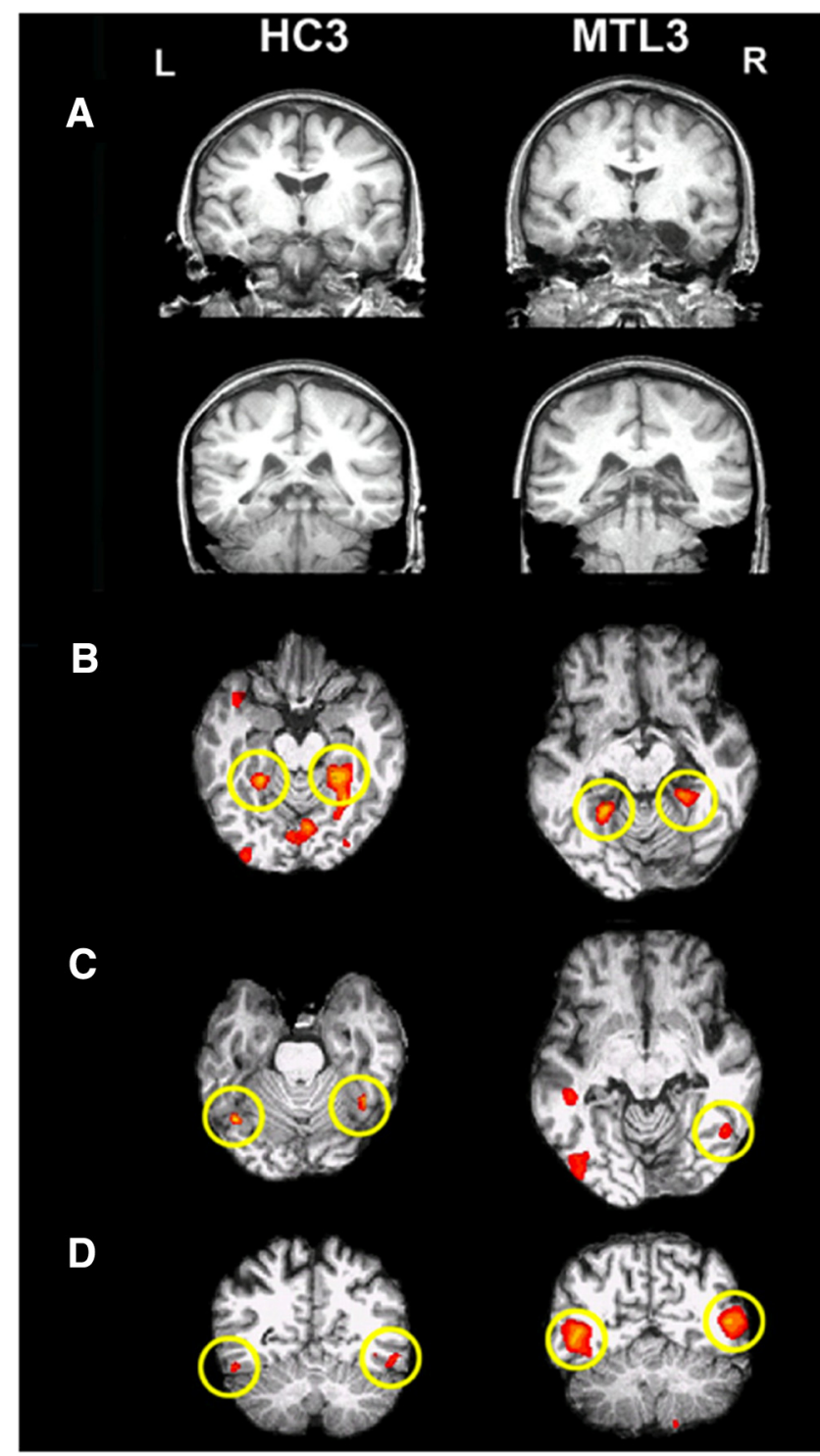

Figure 1. A, Coronal slices from structural T1 images obtained in patients HC3 and MTL3 Detailed information regarding volumetric analysis of these scans is included in Lee and Rudebeck (2010a) (see also Rudebeck et al., 2013, for an examination of resting functional networks and white matter connectivity in these cases). In brief, Lee and Rudebeck (2010a) measured 10 brain regions in each of the right and left hemispheres (temporopolar cortex, amygdala, entorhinal cortex, PrC, HC, parahippocampal cortex, anterior fusiform gyrus, posterior fusiform gyrus, anterior lateral temporal cortex, and posterior lateral temporal cortex). Patient HC3 showed significantly reduced volume compared with healthy controls in the right and left $\mathrm{HC}$ only, whereas patient MTL3 showed reduced volumes bilaterally in the amygdala, entorhinal cortex, PrC, HC, and parahippocampal cortex. MTL3 also showed a significant reduction in brain volume in the right anterior fusiform gyrus and anterior lateral temporal cortex. $\boldsymbol{B}-\boldsymbol{D}$, Activity in parahippocampal and extrastriate areas associated with a functional localizer task in patients HC3 and MTL3 (overlaid on T1-weighted images). $\boldsymbol{B}$, Transverse slices showing PPA based on scenes - (faces + objects). C, Transverse slices showing FFA based on faces - (scenes + objects). $\boldsymbol{D}$, Coronal slices showing lateral occipital cortex based on objects - (scenes + faces). (Permission to reproduce these images from Lee and Rudebeck, 2010a, was granted by A.C.H. Lee).

in age or years of education (all $t<1.07, p>0.30$ ). Ethical approval was obtained from the Cambridge National Health Service Research Ethics Committee. All participants gave informed consent according to the Declaration of Helsinki (1991) regarding involvement in the experiment.

\section{Materials}

Faces. Portrait photographs (grayscale) of two pairs of men and two pairs of women with similar shaped faces and visual features were taken from 
an online yearbook. From these, four morphed face pairs were created using the software package Morpheus 1.85 (ACD Systems; see Mundy et al., 2007, for detailed information about the procedure). In brief, a sequence of intermediate (blended) images were created from a pair of exemplars by anchoring key feature points such as nose, eyes, and mouth and changing the distance between these points (Fig. $2 A$ shows example stimuli pairs). Two faces were then selected from each male and female morph continuums, one of which had $56.6 \%$ of the features of original face 1 and $43.3 \%$ of original face 2 and the other with $43.3 \%$ of face 1 and $56.6 \%$ of face 2 .

Scenes. Four 3D virtual reality, computergenerated rooms were created. A new item was then generated from each of these prototype room layouts ensuring that within the pair there were differences in the size, orientation, and/or location of three of the features of the room (e.g., a window, a staircase, and a wall cavity). In the example pair shown in Figure $2 B$, the two rooms differ in the location of the pillar on the left, the orientation of the right wall, and the angle of the center staircase. The rooms were created using a commercially available computer game (Deus Ex; Ion Storm) and a freeware software editor (Deus Ex Software Development Kit version 1112f).

Dots. A computer program written in Visual Basic was used to generate four pairs of confusable dot patterns (Fig. 2C). The program was constrained to create an initial random pattern of 11 dots of $0.5 \mathrm{~cm}$ radius. A second confusable pattern was made for each initial dot pattern by making random adjustments to the location of 3 dots in the original image within a range of 0.25 to $0.75 \mathrm{~cm}$. All stimuli were $10.2 \times 9.9 \mathrm{~cm}$ when presented on the computer screen.

\section{Experimental procedure}

Stimuli were presented using Presentation (Neurobehavioural Systems) running on either a 17 inch laptop (patients) or an IBM-compatible desktop computer (controls), with the latter connected to a standard 17 inch LCD monitor. Stimuli were shown at a resolution of $1024 \times 786$ pixels. Participants were seated $\sim 60 \mathrm{~cm}$ from the computer screen. After providing informed consent, the first of three exposure-test cycles began with the following instructions appearing on the computer screen:

"You will now see a series of images; some will be very similar. Please pay close attention-the differences are very subtle. (Press the response button to begin)."

Once the response key was pressed, the participants were presented with an item for $2 \mathrm{~s}$, followed by an empty black screen for $0.5 \mathrm{~s}$ (a single trial). They were not required to make any response to these items. As in Mundy et al. (2006), an intermixed presentation schedule was used. For example, within Face Pair 1 (FP1), the two morphed faces (FP1 and FP1') were presented in an intermixed manner one after each other (e.g., FP1, FP1', FP1, FP1'. . .) until there had been 5 presentations of each exemplar (a total of 10 individual trials). The participant was then presented with the stimuli comprising FP2 in the same fashion. Participants then moved on to the test phase.

At the start of the test phase, participants received the following instructions on the computer screen:

"You will now see a second series of images; some will be new. The image will flash-please indicate whether you think the image has changed. Left button $=$ yes, right button $=$ no. (Press the response button to begin)."

During each test trial, participants saw one stimulus for $500 \mathrm{~ms}$, followed by a $300 \mathrm{~ms}$ interstimulus interval (which was filled by a highcontrast mask) and then a second stimulus for $500 \mathrm{~ms}$, which was followed by a $4 \mathrm{~s}$ response period. Two mouse keys were used to record the participants' "yes" and "no" responses. Subsequent trials proceeded
B
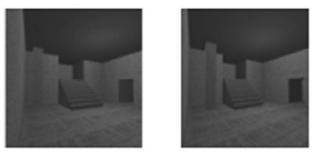

C
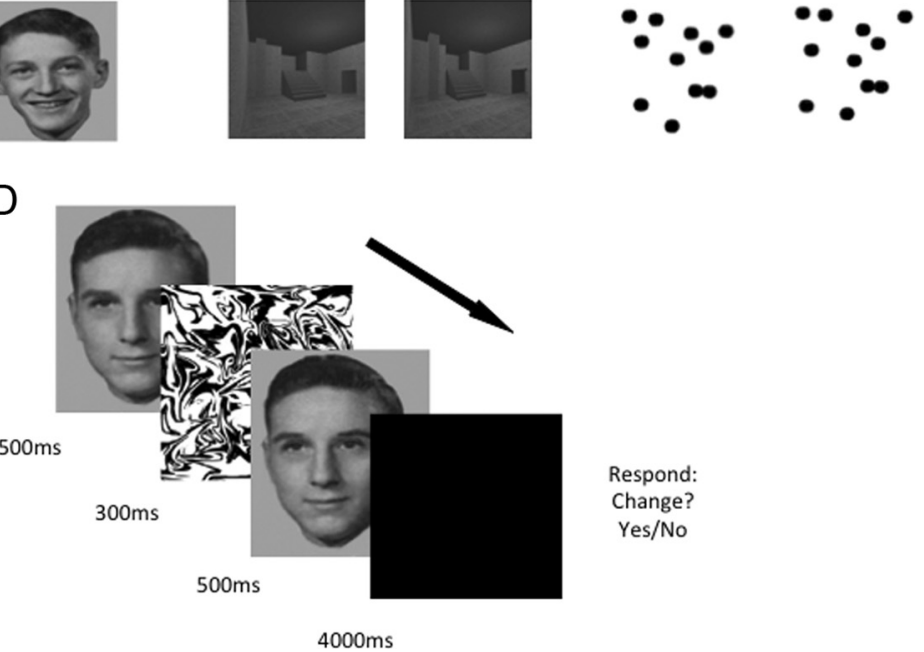

Respond:

es/No

$4000 \mathrm{~ms}$ automatically after the completion of the response period (Fig. $2 D$ is a schematic of a test trial).

In each of the three separately run conditions (faces, scenes, and dots), there were 64 test trials consisting of 16 trials for each of the stimulus pairs seen in the exposure phase, and 16 trials for each of the two pairs not seen in the exposure phase. Half of the presentations of each item pair were "same" trials (e.g., either FP1 then FP1 or FP1' then FP1') and half were "different" trials (e.g., either FP1 then FP1' or FP1' then FP1). The order of same and different trials within a run was randomized, with the restriction that no more than two of each type of trial could occur in succession. Furthermore, the order of trials was randomized with the constraint that there must be eight trials from each condition (preexposed or nonexposed) in every 16 trials. After every 16 trials, a fixation cross was presented for $20 \mathrm{~s}$ to allow the participant to rest. At the completion of the test phase, participants were allowed to rest for 5 min before moving on to the next exposure-test cycle with a different type of stimulus. Patient HC3 was tested on dots, then faces, then scenes; her controls received the same sequence. Patient MTL3 was tested on dots, then scenes, then faces; her controls received the same sequence.

\section{Data analysis}

The data were analyzed in two ways. In Analysis 1A, we investigated whether participants would show any benefit of prior exposure to stimuli by comparing discrimination performance (both accuracy and RT) for preexposed pairs compared with nonexposed pairs. Analysis 1B investigated whether the patients, compared with their controls, showed any evidence of learning across the nonexposed (and preexposed) pairs by looking for improvement in accuracy over four separate time blocks of the test phase (Block 1 to Block 4).

\section{Experiment 2: fMRI in healthy participants Participants}

Sixteen right-handed healthy participants (10 male) were scanned. The ages of the participants ranged from 18 to 40 years (mean, 30) and all had normal or corrected-to-normal vision. All participants gave written informed consent for their participation in the study (according to the Declaration of Helsinki, 1991). This work received ethical approval from the Cardiff University School of Psychology Research Ethics Committee.

\section{Materials}

Twelve face, 12 scene, and 12 dot pattern pairs were created using the procedure described above (see Materials, Experiment 1). 

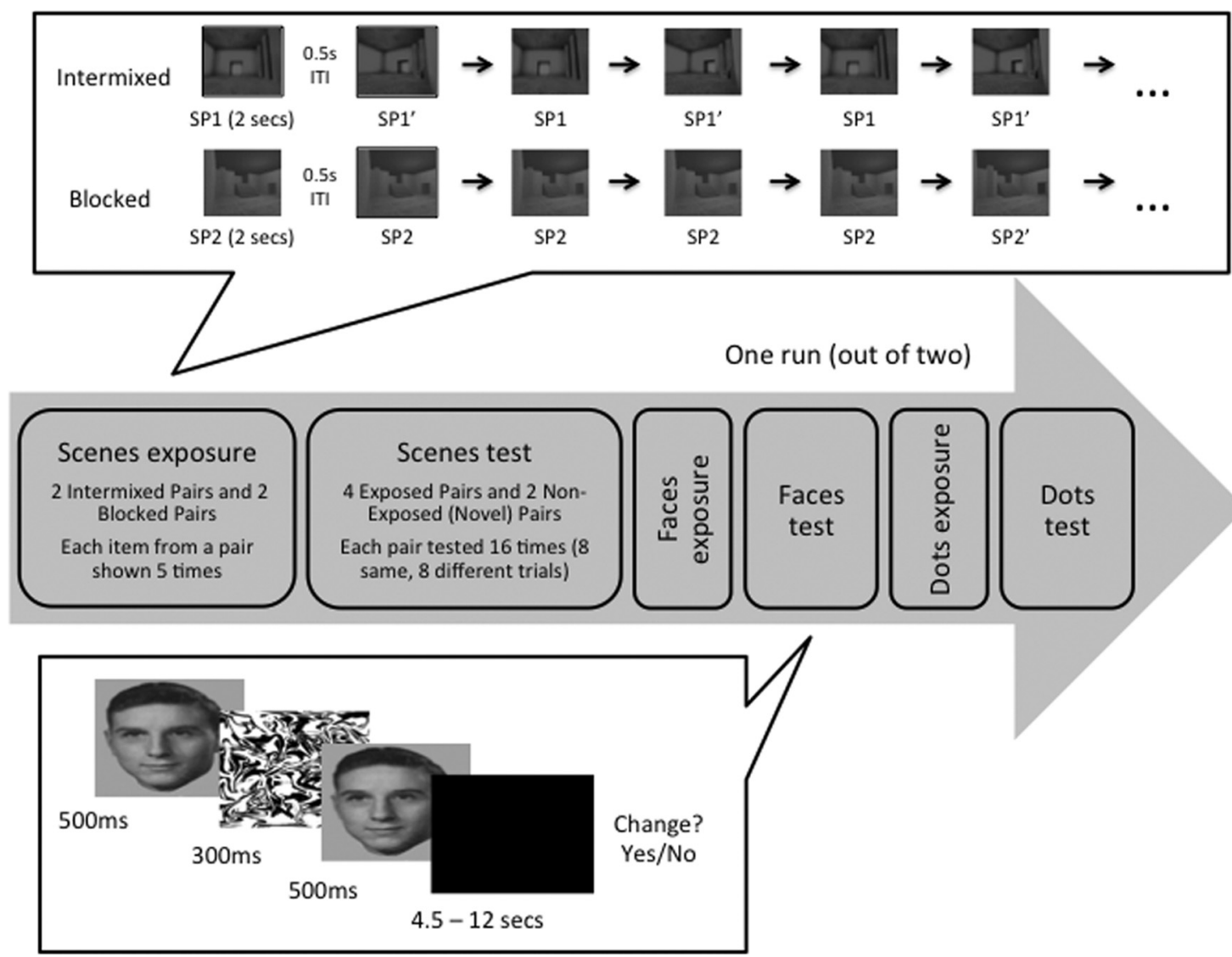

Figure 3. Schematic showing a single run (from one participant) from the fMRI experiment. The top shows the two exposure (intermixed and blocked) conditions. The bottom shows the discrimination test phase (including the timings of stimuli presentation).

\section{Experimental design}

The basic design of the fMRI experiment was similar to Experiment 1 in that participants were exposed to pairs of stimuli at study before undertaking a same/different discrimination task with previously seen, but also nonexposed pairs, at test. One difference, however, was the use of two different preexposure conditions (intermixed and blocked), a manipulation designed to investigate the impact of exposure schedule (Mundy et al., 2009). The full experimental procedure is described below (also see the schematic in Fig. 3), but our statistical analyses were restricted to the preexposed intermixed and nonexposed pairs only.

Stimuli were presented during scanning using Presentation software running on an IBM-compatible desktop computer connected to a digital projector $(1024 \times 786$ pixels resolution). The latter projected onto a white screen situated behind the participant scanner bed and this could be seen via an angled mirror placed directly above the participant's eyes in the scanner. The on-screen dimensions of all images was identical to those in Experiment 1, with stimuli covering $15 \times 12$ degrees of visual angle $(\mathrm{h} \times \mathrm{w})$.

Figure 3 shows the basic experimental design for one run (of two) for a single participant. Within a run, the study phase for one type of stimulus was always followed by the test phase for the same type of stimulus comprising preexposed pairs interspersed with nonexposed pairs from the same category. All stimulus categories appeared equally often in each serial position (presented first, second, or third) within each of the two runs (balanced across participants).

Two preexposure schedules, intermixed and blocked, were used during the study phases. The intermixed preexposure condition was similar to the study phase undertaken by the patients in which the two items comprising a pair were alternately presented (e.g., FP1, FP1', FP1, $\mathrm{FP} 1^{\prime}$... ) until each item in a pair had been viewed five times. The blocked preexposure involved five repetitions of one item from the pair before five presentations of the other item from the pair (FP1, FP1, FP1,
FP1, FP1, FP2. . . ). In both of these conditions, the timing was the same as that in the patient study. Participants were not required to make any response during these preexposure conditions.

During the discrimination test, participants were presented with preexposed pairs from the intermixed and blocked conditions and also nonexposed pairs of faces, scenes, or dots. They indicated whether these pairs were the same or not by pressing the relevant key of a button box held in the right hand. To ensure adequate jitter in trial timings, instead of the $4 \mathrm{~s}$ response window used for the patient study, there was a random intertrial interval of between 4.5 and $12 \mathrm{~s} \mathrm{sampled} \mathrm{from} \mathrm{a} \mathrm{Poisson} \mathrm{distribution.}$ In the test phase, there were 64 preexposed and 32 nonexposed trials in each run, resulting in a total of 64 trials per stimulus type per condition (intermixed, blocked, and nonexposed) across the whole experiment. Trials from pairs seen previously during preexposure were randomly interspersed between nonexposed stimuli trials. Items from each visual category were presented in blocks.

\section{Data acquisition}

Imaging was performed on a General Electric 3T HDx MRI system using an eight-channel receive-only head coil at the Cardiff University Brain Research Imaging Centre, School of Psychology, Cardiff University. For functional imaging, a $\mathrm{T}^{\star}$-weighted gradient-echo, echoplanar imaging (EPI) sequence with high-order shim (HOS) was used to image volumes with BOLD contrast. Fifty slices were collected per image volume covering the whole brain, prescribed 30 degrees inclined from the AC-PC plane (to maximize signal coverage in the MTL). Scanning parameters were as follows: TR/TE, 3000/35 ms; flip angle, 90 degrees; slice thickness, $2.8 \mathrm{~mm}$ ( $1 \mathrm{~mm}$ gap); acquisition matrix GE-EPI, $64 \times 64$; in-plane field of view, $22 \mathrm{~cm}$; ASSET (acceleration factor), 2; and HOS. The HOS is a procedure that allows the scanner to (partially) correct for variations in the magnetic field that arise once a participant is placed in the scanner by adjusting shims inside the gradient coils according to a low-resolution 

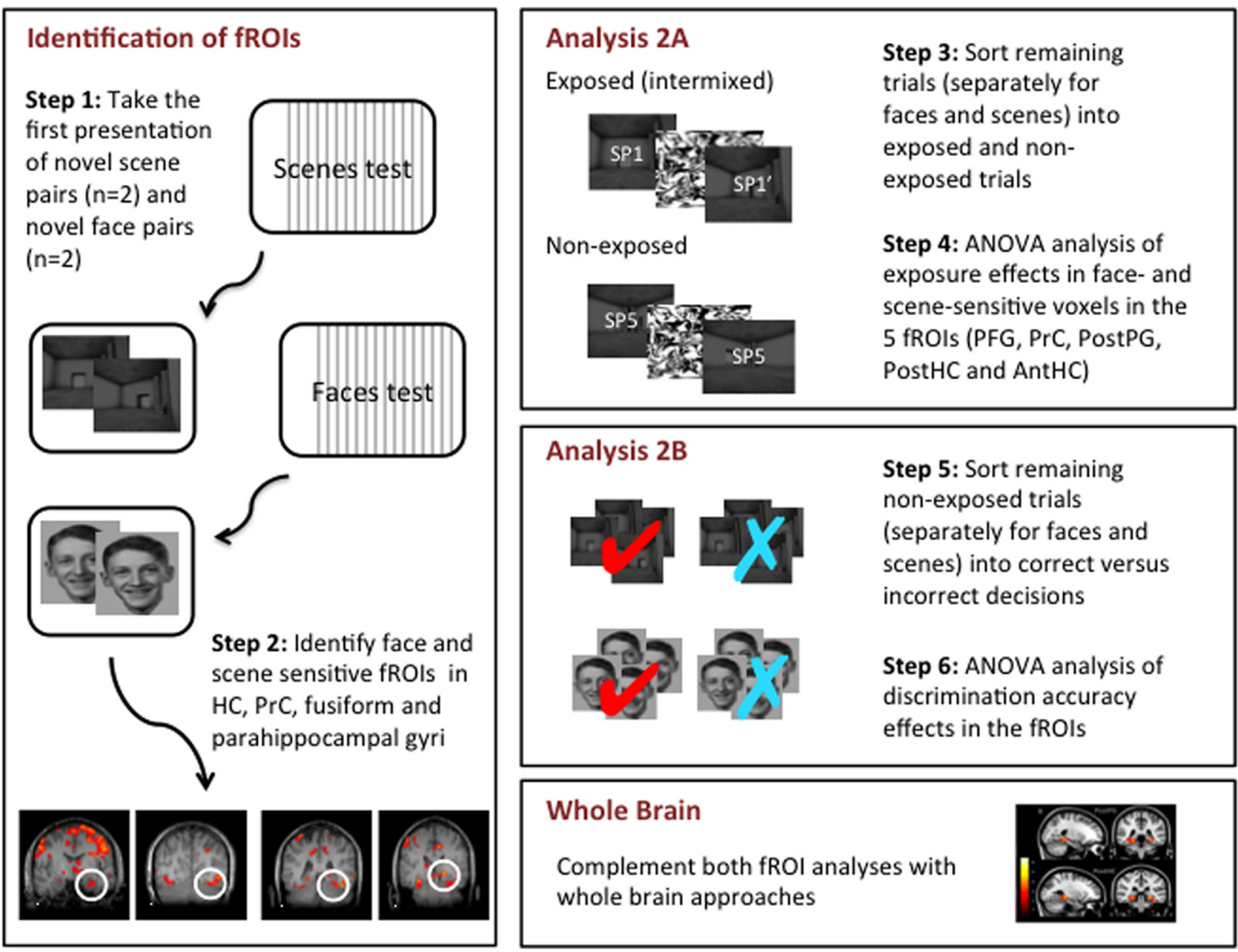

Analysis 2B

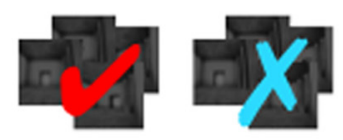

Step 5: Sort remaining non-exposed trials (separately for faces and scenes) into correct versus incorrect decisions

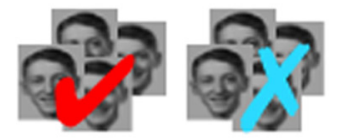

Step 6: ANOVA analysis of discrimination accuracy effects in the fROIs

\section{Whole Brain}

Complement both fROI analyses with whole brain approaches

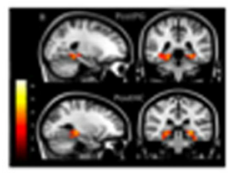

Figure 4. fMRI statistical analysis steps. Left: Identification of the five fROls. Top right: Analyses $2 A$, effect of exposure. Middle right: Analysis $2 B$, discrimination accuracy. Bottom right: Complementary whole-brain analyses.

magnetic field map. Additional high-resolution field maps were also acquired for every participant for the purpose of un-distorting the EPI datasets during image preprocessing. For anatomic localization, a structural scan was obtained for each participant using a T1-weighted sequence (3D FSPGR). Scanning parameters were as follows: TR/TE 7.9/ $3.0 \mathrm{~ms}$; flip angle, 20 degrees; acquisition matrix, $256 \times 256 \times 176$; field of view, $256 \times 256 \times 176 \mathrm{~mm}$; isotropic resolution, $1 \mathrm{~mm}$.

\section{Data preprocessing}

Data preprocessing and statistical analysis of fMRI data were performed using FEAT (fMRI Expert Analysis Tool) Version 5.63, part of the software library of the Oxford Centre for Functional MRI of the Brain (fMRIB) (www.fmrib.ox.ac.uk/fsl). The following prestatistics processing was applied: motion correction using MCFLIRT (Jenkinson et al., 2002); nonbrain removal using BET (Smith, 2002); spatial smoothing using a Gaussian kernel of FWHM $4 \mathrm{~mm}$; mean-based intensity normalization of all volumes; high-pass temporal filtering (Gaussian-weighted leastsquares straight line fitting, with $\sigma=20.0 \mathrm{~s}$ ); and un-distorting the EPI data to correct for magnetic field distortions by means of individual field maps. Time-series statistical analysis was performed using FILM with local autocorrelation correction (Woolrich et al., 2001). Registration to high-resolution 3D anatomical T1 scans ( per participant) and to a standard MNI template image (for group average) was performed using FLIRT (Jenkinson and Smith, 2001; Jenkinson et al., 2002). Coordinates reported here have been converted to Talairach and Tournoux (1988) convention, where appropriate, for ease of comparison with existing literature (Lacadie et al., 2008).

\section{Data analysis: behavioral}

The primary measure of performance was response accuracy ( percentage of correct discriminations) averaged over both scanning runs for each stimulus type (dot patterns, faces, and scenes). RTs during test blocks were also examined to assess whether preexposed compared with nonexposed discriminations were facilitated.

\section{Data analysis: $f M R I$}

We focused on two analyses complementary to the patient study (Fig. 4). Both of these used an fROI approach to investigate how activity in key regions sensitive to faces and scenes was modulated by exposure history (Analysis 2A) and by discrimination accuracy (correct $>$ incorrect, Analysis $2 \mathrm{~B}$ ). The latter was based on pairs presented in the nonexposed condition, but similar findings were evident when we analyzed the intermixed (and blocked) preexposed pairs that were also presented at test. The fROI analyses were complemented, where sensible, with wholebrain contrasts. The procedure for identifying the fROIs is described first, before specific details about the two analyses.

\section{fROI approach}

To mirror procedures used in the visual perception literature, an fROI localizer analysis was performed (Fig. 4, Steps 1 and 2). The following procedures were first performed on individual participant data and then pooled for group-level statistical analysis. To identify orthogonal fROIs for our analysis, the first, completely novel, test trial involving each stimulus pair was used. The first test trial for each face pair was contrasted with the first trial for each scene pair, giving voxel clusters particularly 
Table 1. Previously reported anatomical coordinates for the five fROIs used in Analyses 2A and 2B

\begin{tabular}{|c|c|c|c|c|c|c|c|}
\hline & \multicolumn{6}{|c|}{ Previously reported coordinates } & \multirow[b]{3}{*}{ Reference } \\
\hline & \multicolumn{3}{|l|}{ Left } & \multicolumn{3}{|c|}{ Right } & \\
\hline & $x$ & $y$ & $z$ & $x$ & $y$ & $z$ & \\
\hline PFG & -38 & -46 & -16 & 41 & -47 & -17 & $\begin{array}{l}\text { Peelen and Downing, } 2005 \text { (see also } \\
\text { Kanwisher et al., 1997; Haxby } \\
\text { et al., 2001) }\end{array}$ \\
\hline PostPG & -23 & -44 & -9 & 27 & -40 & -7 & $\begin{array}{l}\text { Peelen and Downing, } 2005 \text { (see also } \\
\text { Epstein and Kanwisher, 1998) }\end{array}$ \\
\hline $\operatorname{PrC}$ & -26 & -9 & -18 & 29 & -9 & -18 & $\begin{array}{l}\text { Lee et al., } 2008 \text { (converted from } \\
\text { MNI space; see also Barense } \\
\text { et al., 2010a, 2011) }\end{array}$ \\
\hline AntHC & -30 & -6 & -18 & 27 & -15 & -18 & $\begin{array}{l}\text { Barense et al., } 2011 \text { (see also Barense } \\
\text { et al., 2010a) }\end{array}$ \\
\hline PosthC & -23 & -29 & 0 & 23 & -32 & 5 & $\begin{array}{l}\text { Lee et al., } 2008 \text { (converted from } \\
\text { MNI space; see also Lee and } \\
\text { Rudebeck, 2010b) }\end{array}$ \\
\hline
\end{tabular}

SDs are shown in parentheses.

activated by faces. The opposite contrast (first trial of each scene pair vs first trial of each face pair) generated voxels particularly activated by scenes. All other further analyses were performed on data from the subsequent trials ( $n=15$ per stimulus pair, a total of 60 per category) with this first novel test trial removed so that localizer and test data were independent, thus avoiding the problem of circularity (Kriegeskorte et al., 2009).

The most significantly active voxel within each anatomical area of interest [i.e., posterior fusiform gyrus (PFG), which includes FFA; posterior parahippocampal gyrus (PostPG), which encompasses PPA); PrC; anterior $\mathrm{HC}$ (AntHC); posterior HC (PostHC)] was located in regions of cortex that corresponded well with previously reported anatomical locations and visible anatomy (Tables 1,2).

Two fROIs were defined for each of our five anatomical areas of interest: one containing any voxels active in the face minus scene localizer contrast, and the other containing any voxels active in the scene minus face localizer contrast. Therefore, each fROI was defined as the set of contiguous voxels that were significantly activated within $12 \mathrm{~mm}$ in the anterior/posterior, superior/inferior, and medial/lateral direction of the peak anatomically constrained voxel in the contrast (Table 1, Table 2). To ensure a liberal inclusion criterion for identification of all domainsensitive voxels involved in the task, a threshold of $p<0.05$ (uncorrected) was used to isolate active voxels.

Analysis 2A: effect of preexposure on learning. fMRI time series data were submitted to a (random effects) general linear model, with one predictor that was convolved with a standard model of the hemodynamic response function for each event type/condition. The regressors were defined by the exposure history of each discrimination event (i.e., "intermixed dots," "blocked dots," "nonexposed dots," "intermixed faces," "blocked faces," "nonexposed faces," "intermixed scenes," "blocked scenes," and "nonexposed scenes"). The first nonexposed trial from each stimulus type was excluded from this analysis because it had been used to generate the independent fROI data; at this point, data from blocked preexposure conditions were also discarded. Multiple linear regression on the time courses resulted in one $\beta$-image for each event type per participant. These parameter estimates were used in a higher-level (group) FLAME analysis (fMRIB's Local Analysis of Mixed Effects; Beckmann et al., 2003; Woolrich et al., 2004).

The parameter estimates within the 10 ROIs identified from our localizer (face-sensitive and scene-sensitive populations of voxels within $\mathrm{PrC}$, AntHC and PostHC, PFG and PostPG) were measured (using Featquery) for intermixed preexposed versus nonexposed faces, scenes and dots (Fig. 4, Steps 3 and 4). A whole-brain contrast between the intermixed preexposed and nonexposed items was also performed for each stimulus category. FEAT's group (Gaussianized) $t$-statistics were converted to $z$-statistics and thresholded using clusters determined by $z>3$ and a (corrected) cluster significance threshold of $p=0.05$ (Worsley et al., 1992).

Analysis 2B: learning of nonexposed pairs over repetition. For Analysis $2 \mathrm{~B}$, we looked at the activity associated with behavioral performance on scene and face nonexposed pairs during their presentation in the test phase. Regressors $(n=32)$ were defined by the stimulus type of each discrimination event and the time point of occurrence (e.g., scene stimuli, first trial; scene stimuli, second trial (i.e., first repeat) ... scene stimuli, sixteenth trial). Each event was further categorized according to behavioral outcome (correct or incorrect discrimination), resulting in four additional regressors (correct scenes, incorrect scenes, correct faces, and incorrect faces). Parameter estimates from the GLM were then combined in a higher-level (group) FLAME analysis (fMRIB's Local Analysis of Mixed Effects; Beckmann et al., 2003; Woolrich et al., 2004) that allowed group-level contrasts.

Data were then submitted to a fROI analysis using the same localizer coordinates used in Analysis 2A. To assess the effect of response accuracy within each of the $10 \mathrm{fROIs}$, the remainder of the discrimination trials (from the second to the sixteenth repeated trials) were separated according to correct versus incorrect discrimination response separately for face and scene trials (Fig. 4, Steps 5 and 6). An average of 40 trials per category per participant were classed as correct responses, with an average of 20 trials classed as incorrect.

For the purposes of the statistical analysis, the functional regions identified in the PostHC, AntHC, and PrC were grouped together as "MTL" regions. Although parahippocampal cortex is anatomically associated with the MTL (Witter, 2002) and necessary for some aspects of long-term memory (Diana et al., 2007, 2010), it is also critical for representing the spatial layout of visual environments (Epstein and Kanwisher, 1998). This perceptual role seems to be functionally different from that played by the HC in scene perception and memory (Epstein et al., 2007; Hartley et al., 2007; Epstein, 2008; Mundy et al., 2012) and more similar to other domain-sensitive areas located on the ventral surface of the temporal lobe (Schwarzlose et al., 2008). Therefore, the domain-sensitive parahippocampal and fusiform fROIs were grouped together (for statistical purposes) as "extrastriate" regions.

For completeness, we also report standard whole-brain accuracy analyses at the end of the Results section.

\section{Results}

\section{Patients: Analysis 1A (the effect of preexposure on learning)}

Figure $5 A$ shows the controls' mean discrimination accuracy for the three stimulus types (scenes, faces, and dots), represented as a percentage difference between performance on pairs of stimuli seen previously (exposed) compared with those not exposed to participants at test. The greater the difference between these two conditions, the larger the perceptual learning effect shown by the controls (and, by extension, patients). Figure $5 \mathrm{~A}$ indicates an average improvement in discrimination accuracy between preexposed and nonexposed pairs of $\sim 12 \%$ in controls, a difference that was significant for all three stimulus types ( smallest $t_{(11)}=$ 18.28, $p<0.01)$. Furthermore, the graph revealed that control performance was well matched across stimulus types, a conclusion supported by an ANOVA revealing no significant effect of stimulus category $\left(F_{(2,22)}=1.7, p=0.193\right)$.

Like controls, patient HC3 showed clear evidence of a benefit of preexposure on her discrimination decisions for dots and faces, with an accuracy difference of $17 \%$ between preexposed and nonexposed conditions. In contrast to the controls, however, she was unable to learn any scene discriminations showing equivalent (chance) performance for both pairs of scenes seen previously and nonexposed scene pairs. Although MTL 3 showed a small difference between the preexposed and nonexposed pairs of scenes $(2 \%)$ and faces (4\%), both of these were well outside the level of perceptual learning demonstrated in the controls, highlighting abnormal discrimination learning for these two stimulus 
Table 2. Talairach and Tournoux (1988) coordinates of the center voxel of each cluster used to produce the 10 fROIs from Analysis 2B

\begin{tabular}{|c|c|c|c|c|c|c|c|c|c|c|c|c|c|c|}
\hline & \multicolumn{6}{|c|}{ Faces $>$ scenes } & \multirow[b]{3}{*}{ Voxels } & \multicolumn{6}{|c|}{ Scenes $>$ faces } & \multirow[b]{3}{*}{ Voxels } \\
\hline & \multicolumn{3}{|l|}{ Left } & \multicolumn{3}{|l|}{ Right } & & \multicolumn{3}{|l|}{ Left } & \multicolumn{3}{|l|}{ Right } & \\
\hline & $x$ & $y$ & $z$ & $x$ & $y$ & $z$ & & $x$ & $y$ & $z$ & $x$ & $y$ & $z$ & \\
\hline PFG & $-38(5)$ & $-46(5)$ & $-17(5)$ & $37(6)$ & $-45(5)$ & $-16(6)$ & $48(7)$ & $-41(8)$ & $-55(9)$ & $-10(8)$ & $41(8)$ & $-53(8)$ & $-12(8)$ & $3(2)$ \\
\hline PostPG & $-21(8)$ & $-39(8)$ & $-6(8)$ & $20(8)$ & $-37(9)$ & $-6(8)$ & $3(2)$ & $-26(6)$ & $-42(7)$ & $-7(5)$ & $27(5)$ & $-40(7)$ & $-7(5)$ & $51(8)$ \\
\hline $\operatorname{PrC}$ & $-26(7)$ & $-8(7)$ & $-18(6)$ & $28(7)$ & $-7(5)$ & $-19(5)$ & $32(5)$ & $-20(6)$ & $-1(7)$ & $-24(6)$ & $22(5)$ & $2(5)$ & $-25(7)$ & $22(5)$ \\
\hline AntHC & $-30(6)$ & $-14(7)$ & $-16(6)$ & $30(7)$ & $-15(7)$ & $-17(6)$ & $11(3)$ & $-31(6)$ & $-20(7)$ & $-12(8)$ & $33(7)$ & $-19(7)$ & $-12(6)$ & $11(3)$ \\
\hline PostHC & $-29(8)$ & $-31(9)$ & $-4(9)$ & $32(8)$ & $-30(8)$ & $-4(8)$ & $12(3)$ & $-28(8)$ & $-35(7)$ & $2(6)$ & $30(5)$ & $-32(7)$ & $2(5)$ & $42(6)$ \\
\hline
\end{tabular}

Data were acquired from the group average $x, y, z(S D)$, along with the mean number of active voxels across both hemispheres.

types. MTL3 was not incapable of any learning, however, as she showed a level of perceptual learning similar to HC3 (and numerically greater than the controls) for dot patterns (16\%). Crawford $t$ test analyses (Crawford et al., 1998; Crawford and Garthwaite, 2002) confirmed that the patients' perceptual learning for dots was not significantly different from controls (all $t \mathrm{~s}<1$ ), but that they had poor perceptual learning for scenes (HC3: $t_{(11)}=5.3$, $p<0.01$; MTL3: $\left.t_{(11)}=4.4, p<0.01\right)$, and, in the case of MTL3, deficient perceptual learning for faces $\left(t_{(11)}=4.2, p<\right.$ 0.01; HC3: $\left.t_{(11)}=1.7, p=0.1\right)$.

Similar stimulus-dependent patterns (in patients) were also evident in the RTs (Fig. 5B). To analyze these data, we collapsed across preexposed and nonexposed trials because statistical analysis (ANOVA for controls; paired one-way $t$ tests for patients) confirmed that there were no significant differences between RTs for preexposed versus nonexposed pairs in controls (all Fs $<1$ ) and that any differences in the RTs obtained for preexposed and nonexposed stimuli in patients were not significantly greater than those seen in the individual controls (true of all conditions). Although RTs were well matched across stimulus type in the controls $(F<$ 1), like the accuracy data, patient $\mathrm{HC} 3$ showed RTs that were similar to controls for dot patterns and faces, but took almost double the time of controls to respond to scene discriminations. Similarly, patient MTL3 showed strikingly longer RTs for scene discriminations; in addition, she was also much slower in her response to the face pair discriminations while responding as fast as controls to dot patterns. Crawford $t$ test analysis confirmed that the RTs obtained for MTL3 in the face and scene conditions (faces: $t_{(11)}=$ 4.3, $p<0.01$; scenes: $\left.t_{(11)}=5.5, p<0.01\right)$ and in HC3 for scene discriminations $\left(t_{(11)}=8.3, p<0.01\right)$ were significantly different from those seen in controls. Critically, HC3 did not show a significantly different pattern in the face condition $(t<1)$, and neither patient was significantly slower than controls when responding to dots (all $t \mathrm{~s}<1$ ).

\section{Patients: Analysis 1B (learning of nonexposed pairs over repetition)}

Complementing these analyses, we also investigated whether the patients showed any learning over repeated presentation of the
Table 3. Behavioral discrimination accuracy (percentage correct) from the fMRI study for the exposed (intermixed) and nonexposed conditions

\begin{tabular}{lll}
\hline & Exposed (intermixed) & Nonexposed \\
\hline Scenes & $81.50(0.221)$ & $66.50(0.237)$ \\
Faces & $83.00(0.199)$ & $68.25(0.289)$ \\
Dots & $82.25(0.242)$ & $66.25(0.237)$ \\
\hline
\end{tabular}

SDs are shown in parentheses.

nonexposed pairs in the discrimination test phase (Fig. 5C). ANOVA confirmed that the controls' discrimination performance to nonexposed stimulus pairs improved over repetition, but did not differ across stimulus type (e.g., there was a significant main effect of block, $F_{(3,9)}=27.63, p<0.01$, but no significant effect of stimulus type or an interaction, $F<1$ ). ANOVA also confirmed significant linear trends in the controls' learning across all stimulus types $\left(F_{(1,11)}=51.63, p<0.01\right)$. To compare the performance of the controls with the patients statistically, 


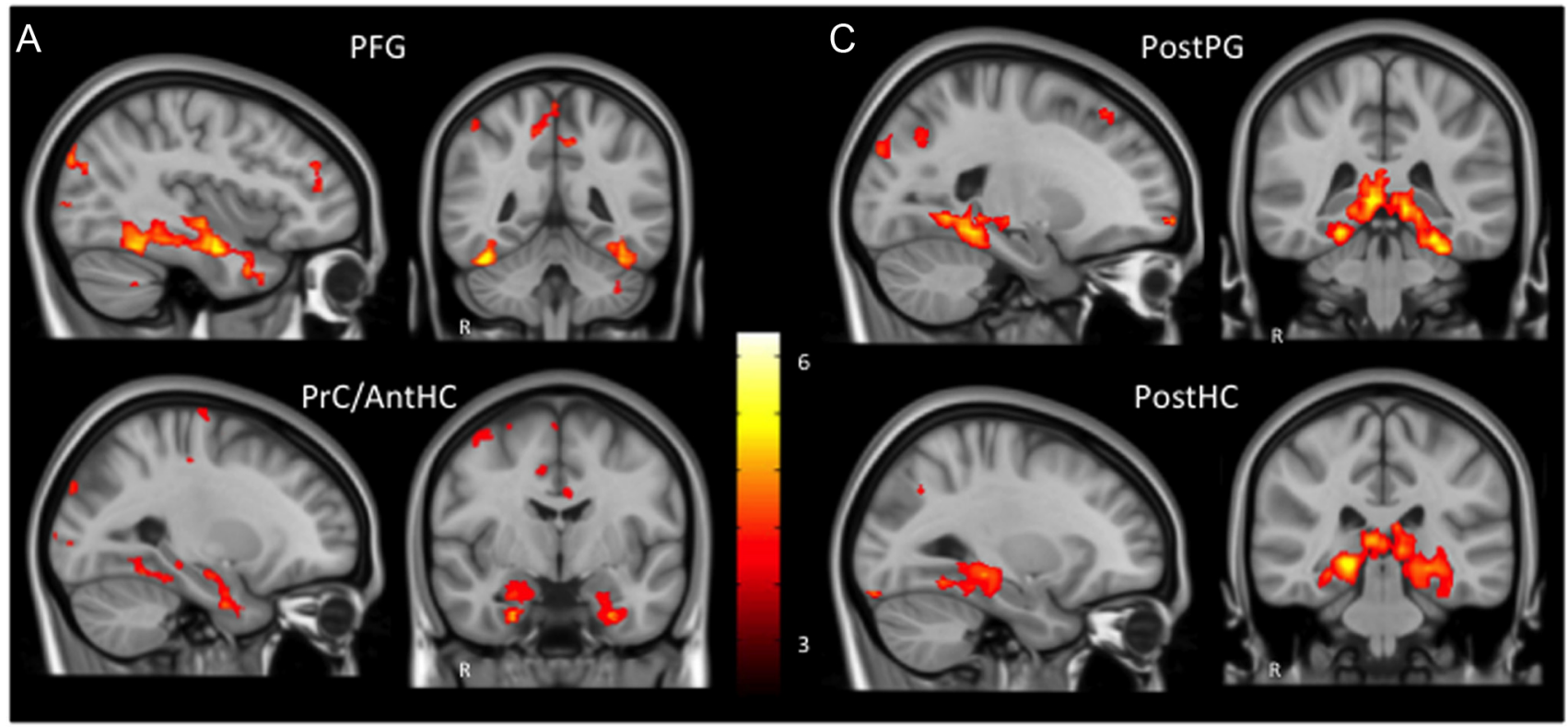

B

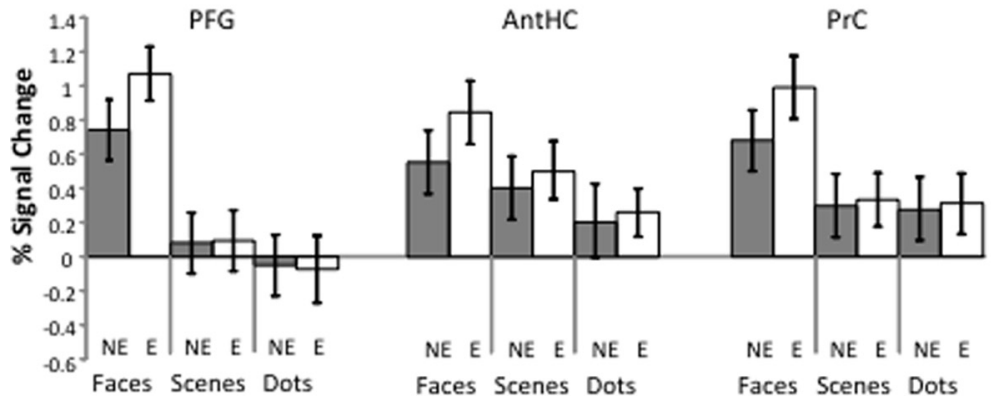

$\mathrm{D}$

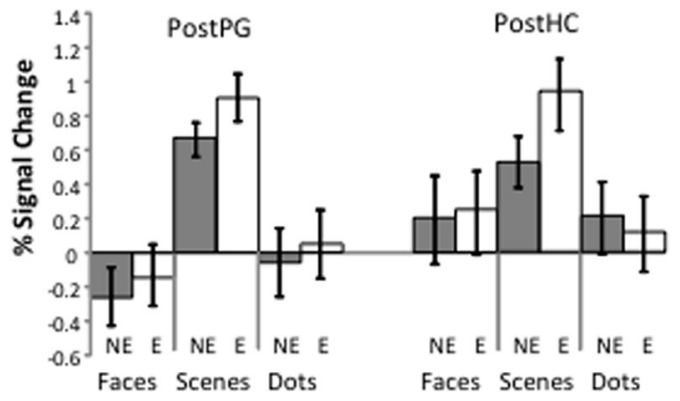

Figure 6. $A, P F G$ (incorporating FFA) and PrC/AntHC activations identified from the fROl analysis. C, PostPG (incorporating PPA) and PostHC activations from the fROl analysis. $B, D$, Parameter estimates obtained from the five fROls (based on their preferred category) for each stimulus type (faces, scenes, and dots) plotted separately for nonexposed (NE) and preexposed (E) conditions in PFG, AntHC, and PrC (face-sensitive voxels; $\boldsymbol{B}$ ) and PostPG and PostHC (scene-sensitive voxels; $\boldsymbol{D}$ ).

improvement was measured by calculating the gradient of the linear trend $(m)$ in learning for each stimulus type as follows: $m=$ $(y-c) / x$, where $c$ is the $y$-axis intercept, $x$-axis is the block number, and $y$-axis is the percentage correct; values obtained for $m=13.02$ for dots $\left(r^{2}=0.94\right), 12.5\left(r^{2}=0.94\right)$ for faces, and $11.77\left(r^{2}=0.99\right)$ for scenes. ANOVA confirmed that there were no differences in these learning profiles $(F<1)$. Although patient HC3 showed a similar learning profile to controls for dots and faces (Crawford $t<1$ ), the gradient of the linear trend for nonexposed scene stimuli was significantly weaker than that of controls $\left(t_{(11)}=4.0, p<0.01\right)$. Patient MTL3 also showed similar performance to controls for dot patterns $(t<1)$, but her learning profile for faces and scenes were significantly weaker than that seen in the controls (faces: $t_{(11)}=3.6, p<0.01$; scenes: $t_{(11)}=4.0$, $p<0.01)$. It is reassuring to note that the same statistically significant patterns were evident over repetition of the preexposed stimuli during the discrimination test phase, although the performance differences between patients and controls were exacerbated by the effect of preexposure itself.

\section{Analysis 2A: fMRI (the effect of preexposure on learning)}

Table 3 shows the discrimination scores obtained for the six experimental conditions. ANOVA revealed a main effect of exposure condition $\left(F_{(1,15)}=45.86, p<0.01\right)$, but no overall effect of stimulus category $(F<1)$ and no interaction $(F<1)$.
Parameter estimates from preexposed (intermixed) and nonexposed face, scene, and dot trials were extracted from the 10 ROIs identified using the localizer. ANOVA revealed a significant four-way interaction of: fROI (PFG, PostPG, PrC, PostHC, AntHC) $\times$ stimulus-sensitive voxels (face-sensitive/scene-sensitive) $\times$ stimulus type (faces/scenes/dots) $\times$ exposure (preexposed/nonexposed) $\left(F_{(8,120)}=15.44, p<0.01\right)$.

Further statistical exploration focusing separately on patterns of activity within face-sensitive voxels and scene-sensitive voxels in the five fROIs, revealed for face-sensitive voxels a significant three-way interaction between stimulus type, exposure, and ROI $\left(F_{(4,60)}=25.01, p<0.01\right.$; Fig. $\left.6 A, B\right)$. Face-sensitive voxels in $\mathrm{PFG}$, AntHC, and PrC showed greater activity to preexposed face pairs than to nonexposed faces (PFG: $t_{(15)}=3.41, p<0.01$; AntHC: $t_{(15)}=2.99, p<0.01$; PrC: $\left.t_{(15)}=3.07, p<0.01\right)$, but there was no modulation of exposure in these three regions for scene or dot pairs $(t<1)$. Face-sensitive voxels in PostPG and PostHC showed no significant differences between preexposed and nonexposed stimuli regardless of stimuli type $(t<1)$.

Turning to scene-sensitive voxels, ANOVA revealed a significant three-way interaction between stimulus type, exposure, and ROI $\left(F_{(2,30)}=19.83, p<0.01\right.$; Fig. $\left.6 C, D\right)$. This interaction reflected greater activation in scene-sensitive voxels in PostPG and PostHC for previously seen pairs of scenes compared with nonexposed pairs (PostPG: $t_{(15)}=2.94, p<0.01$; PostHC: $t_{(15)}=$ 
3.19, $p<0.01)$. Activity associated with preexposed and nonexposed face and dot pairs was not significantly different $(t<$ 1). Similarly, scene-sensitive voxels in PFG, AntHC, and PrC showed no evidence of significantly greater activation for preexposed over nonexposed trials for all stimuli $(t<1)$.

Whole-brain analyses in which the preexposed and nonexposed conditions for faces, scenes, and dots were contrasted (separately by stimulus type) revealed similar findings. For faces, a significant region of BOLD signal change was observed in the lingual gyrus that extended into the inferior occipital gyrus and (temporal/occipital) fusiform gyrus. The extent of this activation likely included FFA. There was also significant activity in the AntHC that extended into the PrC bilaterally ( $\mathrm{L}>\mathrm{R})$. Previously reported anatomical locations place the FFA bilaterally at $-38,-46$, $-16 ; 41,-47,-17$ (Table 1 ), which is close to the peak voxel coordinate in the significant clusters highlighted here: -36 , $-47,-15 ; 35,-43,-14$. The (left) PrC has previously been identified at $-26,-9$, -18 (see MNI space $-27,-7,-25$, Lee et al., 2008), again, almost identical to the significant cluster obtained from our current analysis $(-26,-9,-26)$.

In the scenes contrast, activation was evident in the PostPG (likely encompassing the PPA) and extending bilaterally into PostHC. The PPA has been previously reported at $-23,-44,-9 ; 27,-40$, -7 (Table 1) and the (left) PostHC at $-23,-29,0$ (see MNI space $-24,-29$, -4 , Lee et al., 2008); both of these locations are close to the clusters found here (PostPG: $-21,-39,-6 ; 25,-37,-7$; PostHC: $-26,-33,-4 ;-28,-32,-7)$.

Perceptual learning of dot patterns revealed significant activation in the occipital pole extending into the medial inferior occipital gyrus and lingual gyrus, but no higher-order ventral visual or MTL areas. Because no parahippocampal, fusiform, $\mathrm{HC}$, or PrC activation was found in the dots perceptual learning contrast (preexposed vs nonexposed), this condition was excluded from further analysis.

\section{Analysis 2B: fMRI (learning of nonexposed pairs over repetition)}

Participants showed no overall difference in their averaged discrimination accuracy between stimulus types for the nonexposed trials presented at test (mean faces accuracy: $66.25 \%$, scenes accuracy: $68.55 \%$, dots accuracy: $66.56 \% ; F<1$ ). Similarly, there was no overall difference in RTs (mean faces RT: 1.40 s, scenes RT: 1.43 s, dots RT: $1.40 ; F<1$ ). There was also no significant difference in participants' use of "same" or "different" responses in any of the stimulus types $(t<1)$, suggesting no response bias. Furthermore, there were no significant differences in the accuracy evident on
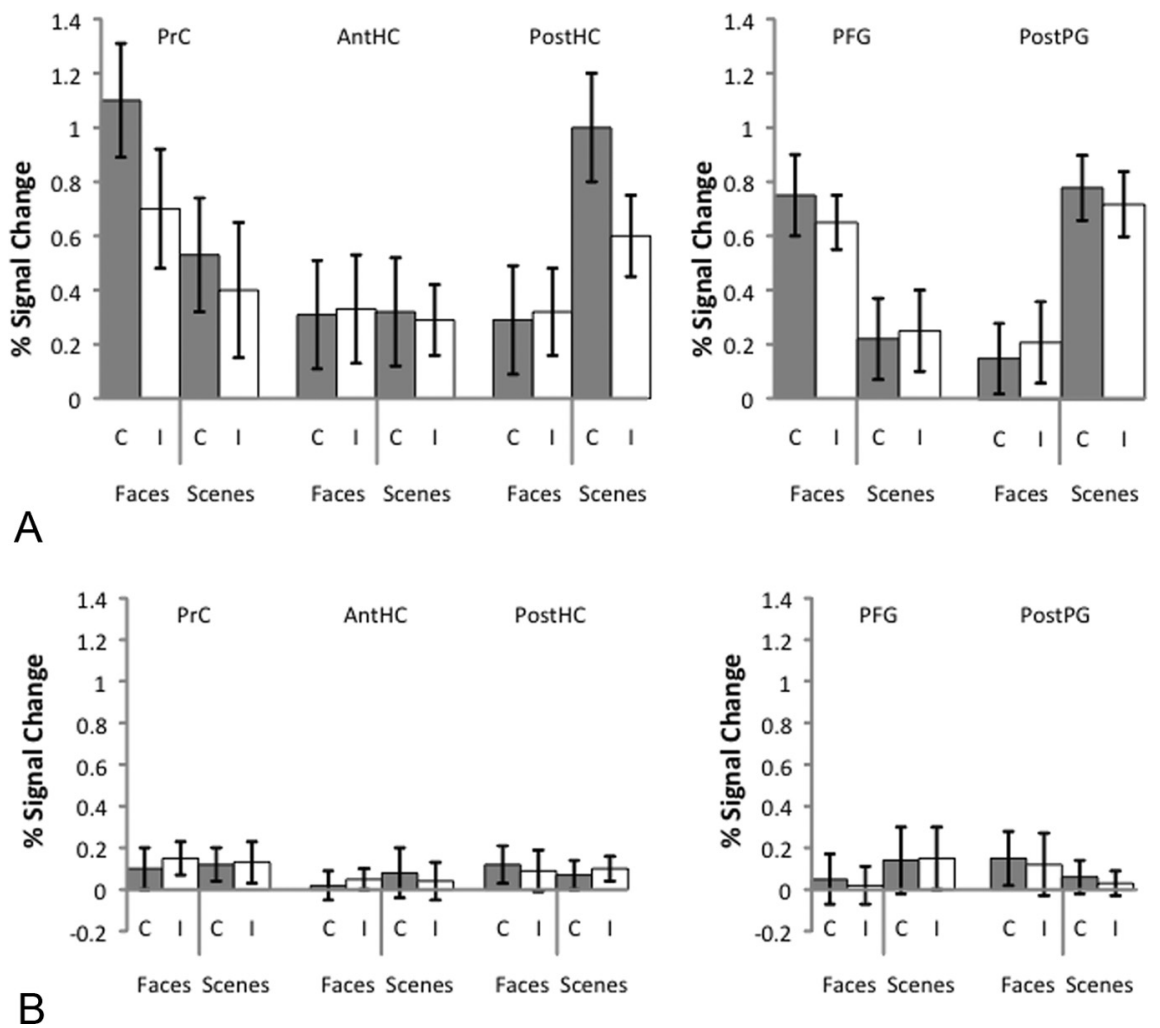

Figure 7. A, Percentage signal change in face-sensitive and scene-sensitive PostHC and PrC ROls (left) and parahippocampal/ fusiform ROls (right) for correct (C, gray bars) and incorrect (I, white bars) discriminations from preferred categories (e.g., face trials ials in scene-sensitive areas) across all ROls. Nonpreferred categories showed no evidence of significant accuracy effects (con-

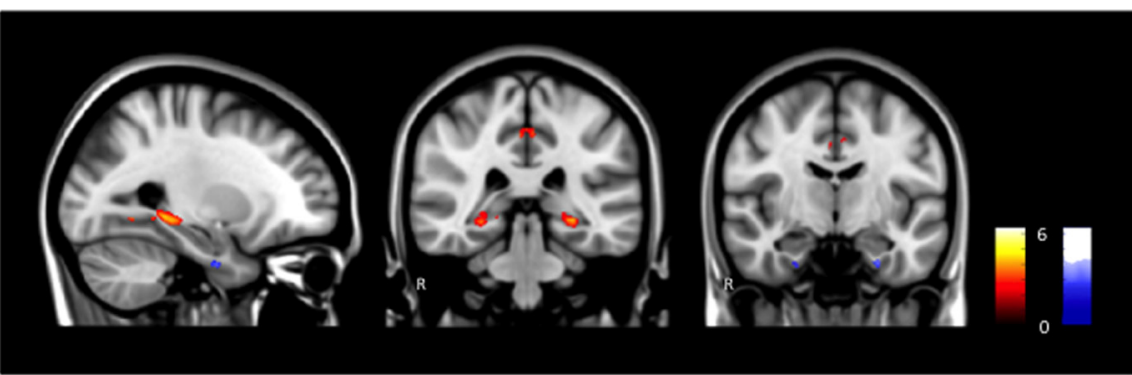

Figure 8. Activations from the whole-brain contrasts of correct nonexposed face discriminations versus incorrect nonexposed face discriminations ( $\operatorname{PrC}$ bilaterally, in blue) and correct nonexposed scene discriminations versus incorrect nonexposed scene discriminations (PostHC bilaterally, in red).

"same" compared with "different" responses for any stimulus type (largest $\left.t_{(15)}=1.73, p=0.104\right)$.

Turning to the analysis of the data obtained from the 10 fROIs (face-sensitive and scene-sensitive populations of voxels within PrC, AntHC and PostHC, PFG and PostPG), we found a significant four-way interaction of area (extrastriate/MTL) $\times$ stimulussensitive voxels (face-sensitive/scene-sensitive) $\times$ stimulus type (faces/scenes) $\times$ response accuracy (correct/incorrect) $\left(F_{(1,15)}=\right.$ $15.78, p<0.01)$. It is worth noting that although this accuracy analysis, like that of the patients in Experiment 1, focused on the nonexposed trials, an equivalent analysis can be performed using the previously exposed intermixed stimuli, which also revealed a similar significant four-way interaction $\left(F_{(1,15)}=12.22, p<0.01\right)$.

Although extrastriate regions showed a main effect of stimulus type $\left(F_{(1,15)}=18.35, p<0.01\right)$ qualified by an interaction between 
stimulus-sensitive subregion (PFG/PostPG) and stimulus type $\left(F_{(1,15)}=34.27, p<0.01\right)$, there was no significant effect of discrimination accuracy and no three-way interaction (all $F_{s}<1$; Fig. $7 A$, right). In contrast, the MTL showed a significant threeway interaction $\left(F_{(2,30)}=18.94, p<0.01\right.$; Fig. $7 A$, left $)$. Facesensitive voxels in $\operatorname{PrC}$ were associated with discrimination accuracy for faces $\left(t_{(15)}=4.55, p<0.01\right)$, but not scenes $(t<1)$, but scene-sensitive PrC voxels did not show any significant change in activity for either category of stimuli $(t<1.4)$. In PostHC, scene-sensitive voxels were associated with discrimination accuracy for scenes $\left(t_{(15)}=3.43, p<0.01\right)$, but not for faces $(t<1)$, whereas face-sensitive PostHC voxels were not involved in successful discrimination performance for either category $(t<1)$.

Voxels within the AntHC were not associated with accuracy for either faces or scenes $(t<1)$ and thus will not be considered further. Analyses of activity by accuracy for the nonpreferred category in each voxel population revealed no statistically significant effects (all Fs $<1$; Fig. $7 B$ ).

Consistent with our fROI analysis, whole-brain analysis also revealed involvement of the $\mathrm{PrC}$ and PostHC in discrimination accuracy for nonexposed faces and scenes, respectively (Fig. 8). BOLD activity relating to accurate discrimination for faces alone and scenes alone was defined by contrasting correct versus incorrect nonexposed trials. This contrast was performed with a random-effects model and tested at an uncorrected threshold of $p<0.001$. When this analysis was conducted with face stimuli (i.e., correct nonexposed faces vs incorrect nonexposed faces), it revealed activation centered on $\operatorname{PrC}(-26,-10,-25 ; 25,-12$, -25 ), with no further areas of significant BOLD activation. A similar contrast of correct versus incorrect nonexposed scene trials revealed activation in PostHC $(-25,-35,-3 ; 27,-34$, $-5)$, with no further areas of significant activity. Furthermore, equivalent patterns of domain-sensitive MTL activity were evident if preexposed stimuli were analyzed and when both nonexposed and preexposed were pooled together.

These findings were further complemented by a whole-brain comparison in which we investigated whether there were any brain areas showing a domain-general pattern as measured by a significant difference in activity for correct discriminations compared with incorrect discriminations across all trial types (i.e., correct scenes + correct faces vs incorrect scenes + incorrect faces). This contrast was performed with a random-effects model and tested at an uncorrected threshold of $p<0.001$. No areas in the MTL, parahippocampal, or fusiform cortex showed a significant domain-general pattern of activation for correct compared with incorrect discriminations. There was, however, a single cluster of activation revealed in lingual gyrus, corresponding to early visual cortex. The results of this analysis do not change if dot trials are included (e.g., correct faces + correct scenes + correct dots minus incorrect faces + incorrect scenes + incorrect dots).

\section{Discussion}

In Experiment 1, $\mathrm{HC}$ damage resulted in impaired scene, but not face or dot pattern, discrimination learning. Broader MTL involvement, including the $\mathrm{HC}$ and $\mathrm{PrC}$, affected scene and face, but spared dot learning. These distinct patterns were evident on two measures: (1) a comparison of performance on preexposed versus nonexposed discriminations and (2) learning of nonexposed (and preexposed) discriminations over repetition at test. There was no hint that the patients' preserved learning was abnormal; both patients performed as well as controls for accuracy and their RTs were equivalent to controls when they showed good perceptual learning. These findings complement Graham et al. (2006), in which three patients with bilateral HC damage (including the patient reported here) showed slowed RTs (but normal accuracy) to scene categorization and learning. Our study extends the conclusions from that study, however, by demonstrating a clear impact on accuracy as well as RTs, revealing a $\mathrm{PrC}$ contribution to face perceptual learning, and showing normal dot pattern discrimination learning using an identical task. The latter finding is important: normal perceptual learning in amnesia is often demonstrated with a dot prototype learning paradigm (Knowlton and Squire, 1993; Kolodny, 1994; Squire and Knowlton, 1995). Our patients showed normal learning on this paradigm (Graham et al., 2006) and, as revealed here, for dot discrimination learning using a different experimental task. Because the patients did not show evidence of normal perceptual learning across all visual categories, however, our study reveals that the type of information to be acquired is a key factor in driving performance on perceptual learning tasks.

In Experiment 2, we obtained complementary evidence that the Post $\mathrm{HC}$ and $\mathrm{PrC}$ were involved in discrimination learning for scenes and faces, respectively. Activity within face-sensitive, but not scene-sensitive, voxels in $\mathrm{PrC}$ and scene-sensitive, but not face-sensitive, voxels in PostHC was modulated by discrimination accuracy (correct $>$ incorrect) at test for both nonexposed and previously exposed pairs. Whole-brain analysis also revealed a similar domain-sensitive, accuracy-dependent pattern in the PostHC and PrC. In contrast, activity in the parahippocampal cortex and fusiform gyrus distinguished between preferred and nonpreferred categories (scenes vs faces), but was not modulated by discrimination accuracy (see also O'Neil et al., 2009, in which fusiform gyrus showed more limited accuracy effects compared with the PrC during recognition memory for face stimuli).

In our fMRI experiment, there was no difference in overall accuracy across the three stimulus conditions; participants started at the same baseline and showed the same degree of improvement in their learning of faces and scenes (and also dots). Therefore, differences in the difficulty of learning about faces and scenes cannot explain the fMRI findings, nor can they explain the results of the patient study in which performance was similarly matched. The fMRI results, therefore, imply that the PrC and PostHC subregions that we identified encode face and scene representations (respectively) that are useful in supporting successful discrimination between the highly similar face and scene pairs presented in our experiment. The lack of accuracy effects for nonpreferred categories in the PostHC and PrC fROIs further strengthens this contention.

The results reported here complement animal and human neuropsychological studies highlighting stimulus-sensitive deficits for complex objects and scenes after damage to the MTL (e.g., Buckley et al., 2001; Bussey et al., 2002; Lee et al., 2005a; Saksida et al., 2006; Barense et al., 2007; Bird et al., 2007; Taylor et al., 2007). However, not all focal amnesic patients show such patterns (Levy et al., 2005; Shrager et al., 2006), and there has been heated debate regarding the locus of these cognitive difficulties, including suggestions that some patients have involvement of fusiform and/or parahippocampal areas in addition to their $\mathrm{HC}$ and PrC damage (Squire et al., 2006; Jeneson and Squire, 2012). This view is inconsistent with data showing that the two amnesic patients described here show domain-sensitive responding in PPA for scenes, lateral occipital cortex for objects, and FFA for faces when scanned during a functional localizer task (Lee and Rudebeck, 2010a; Fig. 1). Our neuropsychological and neuroimaging results add weight to this finding, in particular the converging evidence 
that the $\mathrm{HC}$ and $\mathrm{PrC}$ were the critical contributors to successful discrimination learning. Therefore, it seems highly unlikely that the deficits observed here, and in our patients on similar tasks (Barense et al., 2005; Lee et al., 2005b), reflect fusiform and parahippocampal involvement. Instead, this developing body of evidence highlights that the requirement to process conjunctions of visual and/or spatial features appears to be critical in eliciting such impairments in patients (Graham et al., 2010). More explicitly, as argued by Barense et al. (2012), the PrC is necessary for storing unique object representations (with individual object features dependent upon more posterior regions within the brain; Mundy et al., 2012). In contrast, the HC stores the unique spatial layouts of these objects in an environment and may be required when there is repetition of object features, but also of the spatial locations of objects themselves. It remains to be determined whether the $\mathrm{HC}$ is also engaged by conjunctive spatial feature changes within an object in the same way that it processes conjunctive spatial layout changes within a scene containing multiple objects.

Our findings demonstrate that regions beyond visual cortex (Mukai et al., 2007) contribute to short-term discrimination learning, a finding not predicted by some human memory accounts (Diana et al., 2007; Squire et al., 2007; Brown et al., 2010; Montaldi and Mayes, 2010; Ranganath, 2010). It is also controversial whether the role of MTL regions goes beyond long-term memory to short-term memory (Ranganath and Blumenfeld, 2005; Hartley et al., 2007; Lee and Rudebeck, 2010b; Jeneson and Squire, 2012) and even perceptual processing (Lee et al., 2005b; Baxter, 2009; Suzuki, 2009; Barense et al., 2010a,b; Graham et al., 2010; Lee et al., 2012). The domain-sensitive impairments observed in our amnesic subjects are also seen in trial-unique oddity judgements that placed no explicit requirement on remembering stimuli across trials. Patients were presented with different views of the same item (e.g., face, object, or scene) alongside a completely different item and asked to indicate which item was the odd one out (Lee et al., 2005a; Barense et al., 2007). Selective damage to the $\mathrm{HC}$ affected scene oddity judgments, but not judgments on faces or objects, whereas larger lesions to the MTL, including both the $\mathrm{HC}$ and $\mathrm{PrC}$, impaired object, face, and scene, but not color or size, oddity decisions (see also Lee et al., 2006b, for similar findings in dementia and Buckley et al., 2001, for equivalent impairments in nonhuman primates).

FMRI studies using variations of these oddity judgment tasks activate similar regions to those elicited by our visual discrimination paradigm (Lee et al., 2006a, 2008; Devlin and Price, 2007; O’Neil et al., 2009; Barense et al., 2010a, 2011), revealing complementary patterns of domain-sensitive responding in the $\mathrm{HC}$ and PrC across different tasks with varying degrees of mnemonic demand. It is also worth highlighting recent findings from fMRI studies in nonhuman primates revealing multiple temporal lobe brain regions that respond relatively selectively to discrete object categories, including an anterior face patch (Tsao et al., 2003; Pinsk et al., 2005; Rajimehr et al., 2009). The precise functional roles of these more anterior regions in animals have not yet been elucidated, but given the striking convergence between findings from human and nonhuman primate neuropsychological lesion studies (for review, see Saksida and Bussey, 2010), it is possible that the anterior face patch, if analogous to $\operatorname{PrC}$ in humans, may also include complex conjunctive face and/or object representations.

There is accruing evidence that anatomically separate domain-sensitive $\mathrm{HC}$ and $\mathrm{PrC}$ regions represent complex conjunctive stimuli necessary for multiple aspects of human mem- ory, including - as demonstrated here-success on tasks that require learning to make perceptual discriminations between highly visually similar exemplars. Models that focus on a specific role for the $\mathrm{HC}$ in spatial information processing (Hassabis and Maguire, 2009; Bird et al., 2012), as well as accounts that place these findings in an evolutionary context (Murray and Wise, 2010), provide a potential framework within which to understand these domain-sensitive contributions. The challenge for these and related theories is to determine the following: (1) what types of representations are being stored within these domainsensitive subareas and whether these are the only regions that drive such effects, (2) when these regions are necessary (or not) for learning and memory, and (3) how any domain-sensitive parts of the $\mathrm{HC}$ and $\mathrm{PrC}$ may be anatomically and functionally connected with areas involved in binding information across different modalities (Eichenbaum et al., 2007; Graham et al., 2010; Montaldi and Mayes, 2010; Ranganath, 2010). A further issue that requires resolution is the "anatomical" association of PHC with the MTL (Witter, 2002) in the context of a "functional" profile similar to other extrastriate areas (Schwarzlose et al., 2008; Mundy et al., 2012). Consideration of possible anatomical/functional dissociations between anterior and posterior areas of the $\mathrm{PHC}$ and $\mathrm{HC}$ might help to address this issue.

\section{References}

Aly M, Knight RT, Yonelinas AP (2010) Faces are special but not too special: Spared face recognition in amnesia is based on familiarity. Neuropsychologia 48:3941-3948. CrossRef Medline

Barense MD, Bussey TJ, Lee AC, Rogers TT, Davies RR, Saksida LM, Murray EA, Graham KS (2005) Functional specialization in the human medial temporal lobe. J Neurosci 25:10239-10246. CrossRef Medline

Barense MD, Gaffan D, Graham KS (2007) The human medial temporal lobe processes online representations of complex objects. Neuropsychologia 45:2963-2974. CrossRef Medline

Barense MD, Henson RN, Lee AC, Graham KS (2010a) Medial temporal lobe activity during complex discrimination of faces, objects, and scenes: effects of viewpoint. Hippocampus 20:1819-1831. CrossRef Medline

Barense MD, Rogers TT, Bussey TJ, Saksida LM, Graham KS (2010b) Influence of conceptual knowledge on visual object discrimination: insights from semantic dementia and MTL amnesia. Cereb Cortex 20:2568-2582. CrossRef Medline

Barense MD, Henson RN, Graham KS (2011) Perception and conception: temporal lobe activity during complex discriminations of familiar and novel faces and objects. J Cogn Neurosci 23:3052-3067. CrossRef Medline

Barense MD, Groen II, Lee AC, Yeung, LK, Brady SM, Gregori M, Kapur N, Bussey TJ, Saksida LM, Henson RN (2012) Intact memory for irrelevant information impairs perception in amnesia. Neuron 75:157-167. CrossRef Medline

Baxter MG (2009) Involvement of medial temporal lobe structures in memory and perception. Neuron 61:667-677. CrossRef Medline

Beckmann CF, Jenkinson M, Smith SM (2003) General multilevel linear modeling for group analysis in fMRI. Neuroimage 20:1052-1063. CrossRef Medline

Bird CM, Shallice T, Cipolotti L (2007) Fractionation of memory in medial temporal lobe amnesia. Neuropsychologia 45:1160-1171. CrossRef Medline

Bird CM, Bisby JA, Burgess N (2012) The hippocampus and spatial constraints on mental imagery. Front Hum Neurosci 6:142. CrossRef Medline

Brown MW, Warburton EC, Aggleton JP (2010) Recognition memory: material, process, and substrates. Hippocampus 20:1228-1244. CrossRef Medline

Buckley MJ, Charles DP, Browning PG, Gaffan D (2001) Selective perceptual impairments after perirhinal cortex ablation. J Neurosci 118:138149. Medline

Burgess N, Becker S, King JA, O’Keefe J (2001) Memory for events and their spatial context: models and experiments. Philos Trans R Soc Lond B 356:1493-1503. CrossRef Medline

Bussey TJ, Saksida LM, Murray EA (2002) Perirhinal cortex resolves feature 
ambiguity in complex visual discriminations. Eur J Neurosci 15:365-374. CrossRef Medline

Crawford JR, Garthwaite PH (2002) Investigation of the single case in neuropsychology: Confidence limits on the abnormality of test scores and test score differences. Neuropsychologia 40:1196-1208. CrossRef Medline

Crawford JR, Howell DC, Garthwaite PH (1998) Payne and Jones revisited: Estimating the abnormality of test score differences using a modified paired samples $t$ test. J Clin Exp Neuropsychol 6:898-905. CrossRef Medline

Devlin JT, Price CJ (2007) Perirhinal contributions to human visual perception. Curr Biol 17:1484-1488. CrossRef Medline

Diana RA, Yonelinas AP, Ranganath C (2007) Imaging recollection and familiarity in the medial temporal lobe: a three-component model. Trends Cogn Sci 11:379-386. CrossRef Medline

Diana RA, Yonelinas AP, Ranganath C (2008) High-resolution multi-voxel pattern analysis of category selectivity in the medial temporal lobes. Hippocampus 18:536-541. CrossRef Medline

Diana RA, Yonelinas AP, Ranganath C (2010) Medial temporal lobe activity during source retrieval reflects information type, not memory strength. J Cogn Neurosci 22:1808-1818. CrossRef Medline

Duarte A, Henson RN, Graham KS (2011) Stimulus content and the neural correlates of item and source memory. Brain Res 1373:110-123. CrossRef Medline

Eichenbaum H, Yonelinas AP, Ranganath C (2007) The medial temporal lobe and recognition memory. Annu Rev Neurosci 30:123-152. CrossRef Medline

Epstein RA (2008) Parahippocampal and retrosplenial contributions to human spatial navigation. Trends Cogn Sci 12:388-396. CrossRef Medline

Epstein RA, Parker WE, Feiler AM (2007) Where am I now? Distinct roles for parahippocampal and retrosplenial cortices in place recognition. J Neurosci 27:6141-6149. CrossRef Medline

Epstein R, Kanwisher N (1998) A cortical representation of the local visual environment. Nature 392:598-601. CrossRef Medline

Graham KS, Scahill VL, Hornberger M, Barense MD, Lee AC, Bussey TJ, Saksida LM (2006) Abnormal categorization and perceptual learning in patients with hippocampal damage. J Neurosci 26:7547-7554. CrossRef Medline

Graham KS, Barense MD, Lee AC (2010) Going beyond LTM in the MTL: A synthesis of neuropsychological and neuroimaging findings on the role of the medial temporal lobe in memory and perception. Neuropsychologia 48:831-853. CrossRef Medline

Hartley T, Bird CM, Chan D, Cipolotti L, Husain M, Vargha-Khadem F, Burgess N (2007) The hippocampus is required for short-term topographical memory in humans. Hippocampus 17:34-48. CrossRef Medline

Hassabis D, Maguire EA (2009) The construction system of the brain. Philos Trans R Soc Lond B Biol Sci 364:1263-1271. CrossRef Medline

Haxby JV, Gobbini MI, Furey ML, Ishai A, Schouten JL, Pietrini P (2001) Distributed and overlapping representations of faces and objects in ventral temporal cortex. Science 293:2425-2430. CrossRef Medline

Jeneson A, Squire LR (2012) Working memory, long-term memory, and medial temporal lobe function. Learn Mem 19:15-25. CrossRef Medline

Jenkinson M, Smith S (2001) A global optimisation method for robust affine registration of brain images. Med Image Anal 5:143-156. CrossRef Medline

Jenkinson M, Bannister P, Brady M, Smith S (2002) Improved optimization for the robust and accurate linear registration and motion correction of brain images. Neuroimage 17:825-841. CrossRef Medline

Kanwisher N, McDermott J, Chun MM (1997) The fusiform face area: a module in human extrastriate cortex specialized for face perception. J Neurosci 17:4302-4311. Medline

Kim S, Jeneson A, van der Horst AS, Frascino JC, Hopkins RO, Squire LR (2011) Memory, visual discrimination performance, and the human hippocampus. J Neurosci 31:2624-2629. CrossRef Medline

Knowlton BJ, Squire LR (1993) The learning of categories: parallel brain systems for item memory and category knowledge. Science 262:17471749. CrossRef Medline

Kolodny JA (1994) Memory processes in classification learning-an investigation of amnesic performance in categorization of dot patterns and artistic styles. Psych Sci 5:164-169. CrossRef

Kriegeskorte N, Simmons WK, Bellgowan PS, Baker CI (2009) Circular analysis in systems neuroscience: the dangers of double dipping. Nat Neurosci 12:535-540. CrossRef Medline

Lacadie CM, Fulbright RK, Rajeevan N, Constable RT, Papademetris X (2008) More accurate Talairach coordinates for neuroimaging using non-linear registration. Neuroimage 42:717-725. CrossRef Medline

Lee AC, Rudebeck SR (2010a) Human medial temporal lobe damage can disrupt the perception of single objects. J Neurosci 30:6588-6594. CrossRef Medline

Lee AC, Rudebeck SR (2010b) Investigating the Interaction between spatial perception and working memory in the human medial-temporal lobe. J Cogn Neurosci 22:2823-2835. CrossRef Medline

Lee AC, Buckley MJ, Pegman SJ, Spiers H, Scahill VL, Gaffan D, Bussey TJ, Davies RR, Kapur N, Hodges JR, Graham KS (2005a) Specialization in the medial temporal lobe for processing of objects and scenes. Hippocampus 15:782-797. CrossRef Medline

Lee AC, Bussey TJ, Murray EA, Saksida LM, Epstein RA, Kapur N, Hodges JR, Graham KS (2005b) Perceptual deficits in amnesia: challenging the medial temporal lobe 'mnemonic' view. Neuropsychologia 43:1-11. CrossRef Medline

Lee AC, Bandelow S, Schwarzbauer C, Henson RN, Graham KS (2006a) Perirhinal cortex activity during visual object discrimination: an eventrelated fMRI study. Neuroimage 33:362-373. CrossRef Medline

Lee AC, Buckley MJ, Gaffan D, Emery T, Hodges JR, Graham KS (2006b) Differentiating the roles of the hippocampus and perirhinal cortex in processes beyond long-term declarative memory: a double dissociation in dementia. J Neurosci 26:5198-5203. CrossRef Medline

Lee AC, Scahill VL, Graham KS (2008) Activating the medial temporal lobe during oddity judgment for faces and scenes. Cereb Cortex 18:683-696. CrossRef Medline

Lee AC, Yeung LK, Barense MD (2012) The hippocampus and visual perception. Front Hum Neurosci 6:91. CrossRef Medline

Levy DA, Shrager Y, Squire LR (2005) Intact visual discrimination of complex and feature-ambiguous stimuli in the absence of perirhinal cortex. Learn Mem 12:61-66. CrossRef Medline

Montaldi D, Mayes AR (2010) The role of recollection and familiarity in the functional differentiation of the medial temporal lobes. Hippocampus 20:1291-1314. CrossRef Medline

Mukai I, Kim D, Fukunaga M, Japee S, Marrett S, Ungerleider LG (2007) Activations in visual and attention-related areas predict and correlate with the degree of perceptual learning. J Neurosci 27:11401-11411. CrossRef Medline

Mundy ME, Dwyer DM, Honey RC (2006) Inhibitory associations contribute to perceptual learning in humans. J Exp Psychol Anim B 32:178-184. CrossRef Medline

Mundy ME, Honey RC, Dwyer DM (2007) Simultaneous presentation of similar stimuli produces perceptual learning in human picture processing. J Exp Psychol Anim B 33:124-138. CrossRef Medline

Mundy ME, Honey RC, Downing PE, Wise RG, Graham KS, Dwyer DM (2009) Material-independent and material-specific activation in functional MRI after perceptual learning. Neuroreport 20:1397-1401. CrossRef Medline

Mundy ME, Downing PE, Graham KS (2012) Extrastriate and medial temporal lobe regions respond differentially to visual feature overlap within preferred stimulus category. Neuropsychologia 50:3053-3061. CrossRef Medline

Murray EA, Wise SP (2010) What, if anything, can monkeys tell us about human amnesia when they can't say anything at all? Neuropsychologia 48:2385-2405. CrossRef Medline

O’Neil EB, Cate AD, Köhler S (2009) Perirhinal cortex contributes to accuracy in recognition memory and perceptual discriminations. J Neurosci 29:8329-8334. CrossRef Medline

Peelen MV, Downing PE (2005) Within-subject reproducibility of categoryspecific visual activation with functional MRI. Hum Brain Mapp 25:402408. CrossRef Medline

Pinsk MA, DeSimone K, Moore T, Gross CG, Kastner S (2005) Representations of faces and body parts in macaque temporal cortex: a functional MRI study. Proc Natl Acad Sci U S A 102:6996-7001. CrossRef Medline

Preston AR, Bornstein AM, Hutchinson JB, Gaare ME, Glover GH, Wagner $\mathrm{AD}$ (2010) High-resolution fMRI of content-sensitive subsequent memory responses in human medial temporal lobe. J Cogn Neurosci 22:156-173. CrossRef Medline

Rajimehr R, Young JC, Tootell RB (2009) An anterior temporal face patch 
in human cortex, predicted by macaque maps. Proc Natl Acad Sci U S A 106:1995-2000. CrossRef Medline

Ranganath C (2010) A unified framework for the functional organisation of the medial temporal lobes and the phenomenology of episodic memory. Hippocampus 20:1263-1290. CrossRef Medline

Ranganath C, Blumenfeld RS (2005) Doubts about double dissociations between short- and long-term memory. Trends Cogn Sci 9:374-380. CrossRef Medline

Rudebeck SR, Filippini N, Lee AC (2013) Can visual discrimination deficits in amnesia be attributed to the medial temporal lobe? An investigation into the effects of medial temporal lobe damage on brain connectivity. Hippocampus 23:7-13. CrossRef Medline

Saksida LM, Bussey TJ (2010) The representational-hierarchical view of amnesia: translation from animal to human. Neuropsychologia 48:23702384. CrossRef Medline

Saksida LM, Bussey TJ, Buckmaster CA, Murray EA (2006) No effect of hippocampal lesions on perirhinal cortex-dependent feature-ambiguous visual discriminations. Hippocampus 16:421-430. CrossRef Medline

Schwarzlose RF, Swisher JD, Dang S, Kanwisher N (2008) The distribution of category and location information across object-selective regions in human visual cortex. Proc Natl Acad Sci U S A 105:4447-4452. CrossRef Medline

Shrager Y, Gold JJ, Hopkins RO, Squire LR (2006) Intact visual perception in memory-impaired patients with medial temporal lobe lesions. J Neurosci 26:2235-2240. CrossRef Medline

Smith SM (2002) Fast robust automated brain extraction. Hum Brain Mapp 17:143-155. CrossRef Medline

Squire LR, Knowlton BJ (1995) Learning about categories in the absence of memory. Proc Natl Acad Sci U S A 92:12470-12474. CrossRef Medline

Squire LR, Shrager Y, Levy DA (2006) Lack of evidence for a role of medial temporal lobe structures in visual perception. Learn Mem 13:106-107. CrossRef Medline
Squire LR, Wixted JT, Clark RE (2007) Recognition memory and the medial temporal lobe: A new perspective. Nat Rev Neurosci 8:872-883. CrossRef Medline

Suzuki WA (2009) Perception and the medial temporal lobe: Evaluating the current evidence. Neuron 61:657-666. CrossRef Medline

Suzuki WA (2010) Untangling memory from perception in the medial temporal lobe. Trends Cogn Sci 1:195-200. CrossRef Medline

Talairach J, Tournoux P. Co-planar stereotaxic atlas of the human brain: 3-dimensional proportional system-an approach to cerebral imaging. New York: Thieme Medical, 1988.

Taylor KJ, Henson RN, Graham KS (2007) Recognition memory for faces and scenes in amnesia: Dissociable roles of medial temporal lobe structures. Neuropsychologia 45:2428-2438. CrossRef Medline

Tsao DY, Freiwald WA, Knutsen TA, Mandeville JB, Tootell RB (2003) Faces and objects in macaque cerebral cortex. Nat Neurosci 6:989995. CrossRef Medline

Watson HC, Wilding EL, Graham KS (2012) A role for perirhinal cortex in memory for novel object-context associations. J Neurosci 32:44734481. CrossRef Medline

Witter MP 2002 The parahippocampal region: past, present, and future. The parahippocampal region: organization and role in cognitive function (Witter and Wouterlood, eds), pp 3-19. New York: Oxford UP.

Woolrich MW, Ripley BD, Brady M, Smith SM (2001) Temporal autocorrelation in univariate linear modeling of fMRI data. Neuroimage 14: 1370-1386. CrossRef Medline

Woolrich MW, Behrens TE, Beckmann CF, Jenkinson M, Smith SM (2004) Multilevel linear modelling for fMRI group analysis using Bayesian inference. Neuroimage 21:1732-1747. CrossRef Medline

Worsley KJ, Evans AC, Marrett S, Neelin P (1992) A three-dimensional statistical analysis for CBF activation studies in human brain. J Cereb Blood Flow Metab 12:900-918. CrossRef Medline 